\title{
Determination of the degree of randomness in condensation copolymers containing both symmetrical and unsymmetrical monomer units: a theoretical study
}

\author{
Martine Tessier, Alain Fradet *
}

Université Pierre et Marie Curie, Chimie des Polymères, Courrier 0184, 4 Place Jussieu, 75252 Paris Cedex 05, France; Fax (+33) 1-44277054; afr@ccr.jussieu.fr

(Received: May 26, 2003; published: June 22, 2003)

\begin{abstract}
Expressions for the degree of randomness, $B$, and for the number- and weight-average block lengths of condensation copolymers containing both symmetrical $(A A+B B)$ and unsymmetrical $(A B)$ monomer units are established through an approach based on functional group probabilities. Several parameters introduced in literature to characterize randomness in $A A+B B$ condensation copolymers are also calculated using this approach and compared to $B$, showing that they are simple linear or rational functions of $B$. A method for calculating functional group probabilities from the dyad and triad number-fractions determined by NMR spectroscopy is described for poly(ethylene terephthalate)-poly( $\varepsilon$-caprolactone) copolyesters. This method obviously applies to any $A A+B B+A B$ polycondensation and is easily generalizable to other types of condensation copolymers.
\end{abstract}

\section{Introduction}

Theoretical calculations of the number-average block lengths and the degree of 'randomness' or 'blockiness' of condensation polymers have been examined by many authors, mainly on the basis of NMR studies. Yamadera and Murano [1] studied the microstructure of copolyesters obtained by reacting a diol with mixtures of diesters, such as 1,2-ethanediol (E), dimethyl terephthalate (T) and dimethyl sebacate (S) copolyesters (Scheme 1).
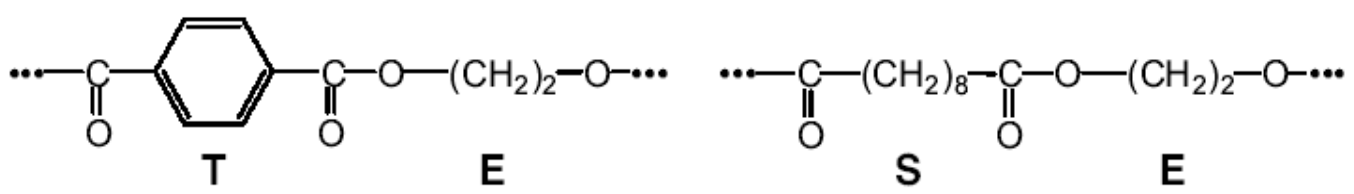

Scheme 1

In order to characterize the copolyester microstructure with a single parameter, they introduced the degree of randomness, $B$, as the sum of the probability $P_{\mathrm{ST}}$ of finding a $\mathrm{T}$ unit next to an $\mathrm{S}$ unit and the probability $P_{\mathrm{TS}}$ of finding an $S$ unit next to a $\mathrm{T}$ unit when inspecting polymer chains from one end to the other: 
Since ST and TS dyads are not present in PET and PES homopolymers, a value of $B=0$ is characteristic of homopolymer mixtures. When $\mathrm{T}$ and $\mathrm{S}$ units are randomly distributed in copolymer chains, $P_{\mathrm{ST}}$ and $P_{\mathrm{TS}}$ are, respectively, equal to the number fractions of $S$ and $T$ units, thus $B=1$. Values $1<B \leq 2$ correspond to the formation of alternating …STSTST $\cdots$ sequences in copolymer chains, while $0<B<1$ would be obtained for block copolymers.

Devaux et al. [2] extended this definition to four-component copolyesters obtained by interchange reactions between $\left(X_{1}+Y_{1}\right)$ and $\left(X_{2}+Y_{2}\right)$ condensation polymers, where the $X_{i}$ 's and $Y_{i}$ 's are mutually reactive difunctional monomers, e.g., diols and dicarboxylic acids. They carried out a theoretical study on the dyad and triad mole ratios and on the number-average sequence lengths in such copolymers and defined the degree of randomness by:

$$
B=P_{\mathrm{X}_{1} \mathrm{Y}_{2}}+P_{\mathrm{Y}_{2} \mathrm{X}_{1}}=P_{\mathrm{X}_{2} \mathrm{Y}_{1}}+P_{\mathrm{Y}_{1} \mathrm{X}_{2}}
$$

where $P_{\mathrm{XY}}$ 's are the probabilities of finding an $\mathrm{X}$ monomer unit followed by a $\mathrm{Y}$ unit in polymer chains.

The degree of randomness $B$ is a very simple and useful parameter to quantify order vs. disorder in copolymers. It has been extensively used to characterize the microstructure of condensation copolymers obtained by reacting mixtures of $A A$ and $B B$ symmetrical monomers, where $A$ and $B$ represent mutually reactive functional groups [3-19]. The run-number $R$, defined as the number of blocks per 100 monomer units [20], and Theil's $Q$ parameter, a measure of randomness [21], were also used for the discussion of ester interchange reorganization in mixtures of polyesters from symmetrical monomers [22].

The definition of $B$ given in Eq. (1) can be easily extended to copolymers obtained by reacting mixtures of unsymmetrical $A B$-type monomers, typically aminoacids, hydroxyacids, lactams or lactones. An example is the study of glycine copolymers of polyamide- 6 and -12 [23]. However, various other randomness parameters have been introduced to study the microstructure of such copolymers: Hetero/homo dyad ratios and average block lengths for copolyamide-6/12 [24] and for copolylactones [25-27]; the ratio, $r$, of random/measured average block lengths, for glycolide-caprolactone copolymers [28]; the 'sequence order parameter' $\Psi$, introduced for copolyesters of 6-hydroxy-2-naphthoic acid and 4-hydroxybenzoic acid [29].

Copolymers containing both symmetrical (AA, BB) and unsymmetrical (AB) monomer units have been much less extensively studied. Moreover, as pointed out by Ma et al. on poly(ethylene terephthalate)-poly( $\varepsilon$-caprolactone) (PET-PCL) copolymers [30], the degree of randomness $B$, as defined in Eqs. (1) and (2), is unsuitable for characterizing the microstructure of such copolymers: Due to the presence of unsymmetrical -O- $\left(\mathrm{CH}_{2}\right)_{5}-\mathrm{CO}$ - units $(\mathrm{L})$ in copolymer chains, the PCL blocks may be connected either to the terephthalate $(T)$ or the 1,2-ethylene $(E)$ units of PET blocks, and there is not always a common unit between PET and PCL blocks. This is not the case in the diol + diacid copolyesters for which the degree of randomness was defined, and using this parameter for copolymers containing unsymmetrical monomer units might lead to misinterpretation of experimental data. Therefore, a variety of more or less complex parameters have been introduced to characterize randomness in such copolymers: The microstructure of aromatic polyesters containing oxybenzoic units [31] and that of copolyamides-6/6.6, $-6 / 4.8$ and -12/6.6 [32,33] have been discussed 
on the basis of hetero/homo dyad ratios and of average sequence lengths. The 'preference parameter' $m$, defined as a ratio of measured/random homo-linkage probabilities, was introduced for poly(4-hydroxy benzoic acid)-poly(butylene terephthalate) copolymers [34]. The sequence order parameter $\Psi$ was used in a modified form for poly(4-hydroxybenzoic acid)-poly( $m$-phenylene terephthalate) copolyesters [35] and a 'randomness number' was defined for copolyesters of PET and poly(4hydroxybenzoic acid) [36].

This paper presents a definition of the degree of randomness $B$ applicable for copolymers containing both symmetrical and unsymmetrical monomer units, taking PET-PCL copolyesters as an example. The various parameters that have been introduced for sequence ordering characterization are also discussed, and a simple method for calculating the degree of randomness and the number- and weightaverage sequence lengths from the dyad or triad number-fractions determined by NMR spectroscopy is also described (see Appendix). The definition of $B$ and the calculation method obviously apply to copolyesters, copolyamides or copolyesteramides containing $A B$ units deriving from aminoacids or hydroxyacids, and more generally to any $A A+B B+A B$ condensation copolymer.

The application of this method to copolyesters obtained by reacting $\varepsilon$-caprolactone with high-molar mass PET in the presence of ester-interchange catalysts will be reported in a forthcoming paper.

\section{Results and discussion}

The microstructure of copolyester chains results from reactions of functional groups, ester interchange between homopolymers or direct esterifications of monomer mixtures. The microstructure is governed by reaction rates when the sequence distribution is kinetically controlled, and by equilibrium constants when it is thermodynamically controlled. In both cases, functional group concentrations are directly involved. It seems, therefore, reasonable to discuss copolymer microstructure on the basis of functional group probabilities, instead of considering monomer unit probabilities as previously done [1,2]. As shown below on PET-PCL copolyesters, this avoids the problems arising from the unsymmetrical nature of AB-type monomers in determining the degree of randomness of copolymers containing both symmetrical and unsymmetrical monomer units.

\section{Definitions and notations}

In the following, the -O- groups of $E$ and $L$ units are noted $A_{E}$ and $A_{L}$, and the $-C O-$ groups of $T$ and $L$ units are noted $B_{T}$ and $B_{L}$, respectively (Scheme 2).
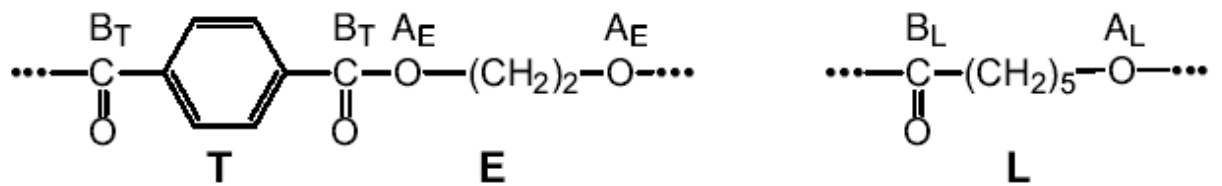

Scheme 2 
Two types of ester bonds can be found when examining a copolymer chain from one end to the other: (i) $A_{L}-B_{L}, B_{L}-A_{L}, A_{E}-B_{T}$ and $B_{T}-A_{E}$, i.e., ester bonds present in the parent homopolyesters, and (ii) $A_{E}-B_{L}, B_{L}-A_{E}, A_{L}-B_{T}$ and $B_{T}-A_{L}$, i.e., hetero-type bonds formed either by ester interchange reactions or by esterification between $L$ reactive groups and $T$ or $E$ reactive groups.

The probability $P\left(A_{i}\right)$ of finding $A_{i}$ groups during polymer chain inspection is defined by Eq. (3), where $N\left(\mathrm{~A}_{\mathrm{i}}\right)$ is the number of $\mathrm{A}_{\mathrm{i}}$ groups and $N(\mathrm{~A})$ is the total number of $\mathrm{A}$ groups. A symmetrical definition applies for $P\left(\mathrm{~B}_{\mathrm{j}}\right)$ (Eq. (4)).

$$
\begin{aligned}
& P\left(\mathrm{~A}_{\mathrm{i}}\right)=\frac{N\left(\mathrm{~A}_{\mathrm{i}}\right)}{N(\mathrm{~A})} \quad(\mathrm{i}=\mathrm{E}, \mathrm{L}) \\
& P\left(\mathrm{~B}_{\mathrm{j}}\right)=\frac{N\left(\mathrm{~B}_{\mathrm{j}}\right)}{N(\mathrm{~B})} \quad(\mathrm{j}=\mathrm{T}, \mathrm{L})
\end{aligned}
$$

Neglecting the contribution of end-groups, i.e., assuming that $A$ and $B$ are in stoichiometric ratio and copolymer molar mass is high, the total number of ester bonds present in copolymer chains is equal to the total number of $A$ groups (or $B$ groups). Consequently, the probability of finding $A_{i}-B_{j}$ or $B_{j}-A_{i}$ ester bonds (irrespective of the ester bond direction) is:

$$
P\left(\mathrm{~A}_{\mathrm{i}} \mathrm{B}_{\mathrm{j}}\right)=\frac{N\left(\mathrm{~A}_{\mathrm{i}} \mathrm{B}_{\mathrm{j}}\right)}{N(\mathrm{~A})} \quad(\mathrm{i}=\mathrm{E}, \mathrm{L} ; \mathrm{j}=\mathrm{T}, \mathrm{L})
$$

where $N\left(\mathrm{~A}_{\mathrm{i}}, \mathrm{B}_{\mathrm{j}}\right)=N\left(\mathrm{~B}_{\mathrm{j}}, \mathrm{A}_{\mathrm{i}}\right)$ is the number of $\mathrm{A}_{\mathrm{i}}-\mathrm{B}_{\mathrm{j}}+\mathrm{B}_{\mathrm{j}}-\mathrm{A}_{\mathrm{i}}$ ester bonds found during polymer chain inspection.

Since the total number of ester bonds involving $A_{i}$ groups is equal to the number of $A_{i}$ groups, the conditional probability $P\left(B_{j} \mid A_{i}\right)$ of finding a $B_{j}$ group given that the other group of the ester bond is an $A_{i}$ group can be defined as follows:

$P\left(\mathrm{~B}_{\mathrm{j}} \mid \mathrm{A}_{\mathrm{i}}\right)=\frac{N\left(\mathrm{~A}_{\mathrm{i}} \mathrm{B}_{\mathrm{j}}\right)}{N\left(\mathrm{~A}_{\mathrm{i}}\right)}=\frac{P\left(\mathrm{~A}_{\mathrm{i}} \mathrm{B}_{\mathrm{j}}\right)}{P\left(\mathrm{~A}_{\mathrm{i}}\right)} \quad(\mathrm{i}=\mathrm{E}, \mathrm{L} ; \mathrm{j}=\mathrm{T}, \mathrm{L})$

Eq. (6) shows that $P\left(\mathrm{~B}_{\mathrm{j}} \mid \mathrm{A}_{\mathrm{i}}\right)$ is the number-fraction of $\mathrm{A}_{\mathrm{i}}$ groups that are linked to $\mathrm{B}_{\mathrm{j}}$ groups. Symmetrical definitions apply for the $P\left(\mathrm{~A}_{\mathrm{i}} \mid \mathrm{B}_{\mathrm{j}}\right)$ probabilities:

$P\left(\mathrm{~A}_{\mathrm{i}} \mid \mathrm{B}_{\mathrm{j}}\right)=\frac{P\left(\mathrm{~A}_{\mathrm{i}} \mathrm{B}_{\mathrm{j}}\right)}{P\left(\mathrm{~B}_{\mathrm{j}}\right)} \quad(\mathrm{i}=\mathrm{E}, \mathrm{L} ; \mathrm{j}=\mathrm{T}, \mathrm{L})$

From Bayes' theorem on conditional probabilities, and remarking that $A_{i}$ groups can be linked to $B_{T}$ or $B_{L}$ only and $B_{j}$ groups to $A_{E}$ or $A_{L}$ only, it follows:

$$
\begin{aligned}
& P\left(\mathrm{~B}_{\mathrm{T}} \mid \mathrm{A}_{\mathrm{E}}\right) P\left(\mathrm{~A}_{\mathrm{E}}\right)=P\left(\mathrm{~A}_{\mathrm{E}} \mid \mathrm{B}_{\mathrm{T}}\right) P\left(\mathrm{~B}_{\mathrm{T}}\right) \\
& P\left(\mathrm{~B}_{\mathrm{T}} \mid \mathrm{A}_{\mathrm{L}}\right) P\left(\mathrm{~A}_{\mathrm{L}}\right)=P\left(\mathrm{~A}_{\mathrm{L}} \mid \mathrm{B}_{\mathrm{T}}\right) P\left(\mathrm{~B}_{\mathrm{T}}\right) \\
& P\left(\mathrm{~B}_{\mathrm{L}} \mid \mathrm{A}_{\mathrm{E}}\right) P\left(\mathrm{~A}_{\mathrm{E}}\right)=P\left(\mathrm{~A}_{\mathrm{E}} \mid \mathrm{B}_{\mathrm{L}}\right) P\left(\mathrm{~B}_{\mathrm{L}}\right) \\
& P\left(\mathrm{~B}_{\mathrm{L}} \mid \mathrm{A}_{\mathrm{L}}\right) P\left(\mathrm{~A}_{\mathrm{L}}\right)=P\left(\mathrm{~A}_{\mathrm{L}} \mid \mathrm{B}_{\mathrm{L}}\right) P\left(\mathrm{~B}_{\mathrm{L}}\right)
\end{aligned}
$$

$$
\begin{aligned}
& P\left(\mathrm{~B}_{\mathrm{T}} \mid \mathrm{A}_{\mathrm{E}}\right)+P\left(\mathrm{~B}_{\mathrm{L}} \mid \mathrm{A}_{\mathrm{E}}\right)=1 \\
& P\left(\mathrm{~B}_{\mathrm{T}} \mid \mathrm{A}_{\mathrm{L}}\right)+P\left(\mathrm{~B}_{\mathrm{L}} \mid \mathrm{A}_{\mathrm{L}}\right)=1 \\
& P\left(\mathrm{~A}_{\mathrm{E}} \mid \mathrm{B}_{\mathrm{T}}\right)+P\left(\mathrm{~A}_{\mathrm{L}} \mid \mathrm{B}_{\mathrm{T}}\right)=1 \\
& P\left(\mathrm{~A}_{\mathrm{E}} \mid \mathrm{B}_{\mathrm{L}}\right)+P\left(\mathrm{~A}_{\mathrm{L}} \mid \mathrm{B}_{\mathrm{L}}\right)=1
\end{aligned}
$$

Since stoichiometric considerations lead to $P\left(\mathrm{~A}_{\mathrm{L}}\right)=P\left(\mathrm{~B}_{\mathrm{L}}\right)$ and $P\left(\mathrm{~A}_{\mathrm{E}}\right)=P\left(\mathrm{~B}_{\mathrm{T}}\right)$, the resolution of this equation system leads to the values of conditional probabilities given in Eqs. (16) - (19): 


$$
\begin{aligned}
& P\left(\mathrm{~A}_{\mathrm{E}} \mid \mathrm{B}_{\mathrm{T}}\right)=P\left(\mathrm{~B}_{\mathrm{T}} \mid \mathrm{A}_{\mathrm{E}}\right)=a \\
& P\left(\mathrm{~A}_{\mathrm{L}} \mid \mathrm{B}_{\mathrm{T}}\right)=P\left(\mathrm{~B}_{\mathrm{L}} \mid \mathrm{A}_{\mathrm{E}}\right)=1-a \\
& P\left(\mathrm{~A}_{\mathrm{E}} \mid \mathrm{B}_{\mathrm{L}}\right)=P\left(\mathrm{~B}_{\mathrm{T}} \mid \mathrm{A}_{\mathrm{L}}\right)=\frac{2 t}{l}(1-a) \\
& P\left(\mathrm{~A}_{\mathrm{L}} \mid \mathrm{B}_{\mathrm{L}}\right)=P\left(\mathrm{~B}_{\mathrm{L}} \mid \mathrm{A}_{\mathrm{L}}\right)=1-\frac{2 t}{l}(1-a)
\end{aligned}
$$

where $l$ is the number of $L$ units and $t$ is the number of $T$ units (= number of $E$ units) in the copolymer. If the $t / l$ ratio is known, all conditional probabilities can be calculated, provided that one of them, e.g., $P\left(\mathrm{~B}_{T} \mid \mathrm{A}_{E}\right)=a$, has been experimentally determined. As discussed in the Appendix, this can be carried out via NMR spectroscopy.

\section{Degree of randomness, $B$}

In random PET-PCL copolyesters, the probability of finding an $A_{i}$ group does not depend on the nature of the $B_{j}$ group to which it is linked. From elementary probability theory, the joint probability of two independent events factorizes into the product of the marginal probabilities: $P\left(\mathrm{~A}_{\mathrm{i}}, \mathrm{B}_{\mathrm{j}}\right)=P\left(\mathrm{~A}_{\mathrm{i}}\right) P\left(\mathrm{~B}_{\mathrm{j}}\right)$. Consequently, the degree of randomness, $B$, can be defined as the probability of finding hetero-type bonds divided by the product of the probabilities of finding the corresponding $A$ and $B$ groups in copolymer chains:

$$
B=\frac{P\left(\mathrm{~A}_{\mathrm{E}}, \mathrm{B}_{\mathrm{L}}\right)}{P\left(\mathrm{~A}_{\mathrm{E}}\right) P\left(\mathrm{~B}_{\mathrm{L}}\right)}=\frac{P\left(\mathrm{~A}_{\mathrm{L}}, \mathrm{B}_{\mathrm{T}}\right)}{P\left(\mathrm{~A}_{\mathrm{L}}\right) P\left(\mathrm{~B}_{\mathrm{T}}\right)}
$$

Definitions (5) - (7) lead to the following equivalent relations:

$$
B=\frac{P\left(\mathrm{~A}_{\mathrm{E}} \mid \mathrm{B}_{\mathrm{L}}\right)}{P\left(\mathrm{~A}_{\mathrm{E}}\right)}=\frac{P\left(\mathrm{~B}_{\mathrm{L}} \mid \mathrm{A}_{\mathrm{E}}\right)}{P\left(\mathrm{~B}_{\mathrm{L}}\right)}=\frac{P\left(\mathrm{~A}_{\mathrm{L}} \mid \mathrm{B}_{\mathrm{T}}\right)}{P\left(\mathrm{~A}_{\mathrm{L}}\right)}=\frac{P\left(\mathrm{~B}_{\mathrm{T}} \mid \mathrm{A}_{\mathrm{L}}\right)}{P\left(\mathrm{~B}_{\mathrm{T}}\right)}
$$

When $\mathrm{T}, \mathrm{E}$ and $\mathrm{L}$ units are randomly distributed in polymer chains, $P\left(\mathrm{~A}_{\mathrm{i}} \mid \mathrm{B}_{\mathrm{j}}\right)=P\left(\mathrm{~A}_{\mathrm{i}}\right)$ and $P\left(\mathrm{~B}_{\mathrm{j}} \mid \mathrm{A}_{\mathrm{i}}\right)=P\left(\mathrm{~B}_{\mathrm{j}}\right)$, hence $B=1$. As in the definition of Yamadera and Murano [1], $B<1$ for copolymers having a low content of $A_{E}-B_{L}$ and $A_{L}-B_{T}$ ester bonds, i.e., block-copolymers with long PET or PCL sequences, $B=0$ for homopolymer mixtures, since no hetero-type bonds are present in this case, and $B>1$ reflects a tendency of the copolymer to form alternating sequences.

Since $\Sigma P\left(A_{i}\right)=1$ and $\Sigma P\left(B_{j}\right)=1$, Eqs. (17), (18) and (21) lead to:

$$
B=P\left(\mathrm{~A}_{\mathrm{E}} \mid \mathrm{B}_{\mathrm{L}}\right)+P\left(\mathrm{~B}_{\mathrm{L}} \mid \mathrm{A}_{\mathrm{E}}\right)=P\left(\mathrm{~A}_{\mathrm{L}} \mid \mathrm{B}_{\mathrm{T}}\right)+P\left(\mathrm{~B}_{\mathrm{T}} \mid \mathrm{A}_{\mathrm{L}}\right)
$$

This closely resembles the definition based on monomer units that was introduced by Yamadera and Murano [1] (Eq. (1)) and Devaux et al. [2] (Eq. (2)). In the case of PET-PCL copolymers, however, the definition of $B$ based on monomer units leads to $B=P_{\mathrm{EL}}+P_{\mathrm{LE}}$, where $P_{\mathrm{EL}}$ is the probability of finding an $\mathrm{E}$ unit followed by an $\mathrm{L}$ unit and $P_{\mathrm{LE}}$ the probability of finding an $\mathrm{L}$ unit followed by an $\mathrm{E}$ unit. This definition could result in misleading interpretations, as can be shown on a simple example:

The degree of randomness of an alternating copolymer composed of long ...TELTELTEL $\cdots$ sequences is $B=1$, since all $E$ units are followed by an $\mathrm{L}$ unit $\left(P_{\mathrm{EL}}=1\right)$ while no $\mathrm{L}$ unit is followed by an $\mathrm{E}$ unit $\left(P_{\mathrm{LE}}=0\right)$. Examining the polymer 
chain in the reverse direction would, of course, also lead to $B=1$. This alternating copolymer would thus be erroneously taken as a random copolymer.

On the other hand, applying Eq. (22) in the case of a $\cdots$ TELTELTEL $\cdots$ copolymer yields $B=1.5$, since all $\mathrm{B}_{\mathrm{L}}$ groups are linked to $\mathrm{A}_{\mathrm{E}}$ groups $\left(P\left(\mathrm{~A}_{\mathrm{E}} \mid \mathrm{B}_{\mathrm{L}}\right)=1\right)$ while one half of $A_{E}$ groups are linked to $B_{L}$ groups $\left(P\left(B_{L} \mid A_{E}\right)=0.5\right)$. Therefore, alternating copolymers can be discriminated from random ones $(B=1)$. In a fully alternating copolymer composed of $\cdots$ LTLELTLE $\cdots$ sequences, all $B_{L}$ groups are linked to $A_{E}$ groups, all $A_{E}$ groups are linked to $B_{L}$ groups and the degree of randomness reaches the maximum value $B=2$. According to the definition based on monomer units, $B$ would be only 1.5 in this case.

$B$ can be calculated from NMR data as a function of the $t / l$ ratio and of the value of one of the conditional probabilities, e.g., $P\left(\mathrm{~B}_{\mathrm{T}} \mid \mathrm{A}_{\mathrm{E}}\right)=a$, using Eqs. (16-19 and 20-22):

$B=(1-a) \frac{2 t+l}{l}$

It is easy to verify that $B=1$ for random copolymers $(a=2 t /(2 t+l)), B=1.5$ for alternating $\cdots$ TELTELTEL $\cdots$ copolymers $(a=0.5, l=t)$ and $B=2$ for alternating $\cdots$ LTLELTLE $\cdots$ copolymers $(a=0, l=2 t)$.

Eq. (22) can obviously be applied to copolymers obtained by reacting two AB-type unsymmetrical monomers and also directly applies to the four-component condensation copolymers studied by Devaux et al. [2], yielding the same $B$ values. It can be applied to the three-component copolyesters of Yamadera and Murano [1] if they are considered as copolymers composed of two pseudo AB-type monomer units, TE and SE (see Scheme 1). The definition of the degree of randomness based on functional groups given in Eqs. (20) - (22) is, therefore, of general application.

\section{Run-fraction, $R$}

The run-number or run-fraction, $R$ [20], is commonly used in the NMR literature on copolymers. It is defined as the average number of sequences of various types (runs) per monomer unit (or per 100 monomer units if expressed in \%). The run-fraction reflects the chain regularity disruption and correlates well with the ability of a polymer to crystallize and, therefore, with the properties that are associated with crystallinity, such as density, tensile strength or flexural modulus.

In the case of PET-PCL copolymers, the number of blocks is equal to the number of hetero-type ester bonds:

$$
R=\frac{N\left(\mathrm{~A}_{\mathrm{E}} \mathrm{B}_{\mathrm{L}}\right)+N\left(\mathrm{~A}_{\mathrm{L}}, \mathrm{B}_{\mathrm{T}}\right)}{N(\mathrm{E})+N(\mathrm{~T})+N(\mathrm{~L})}=P\left(\mathrm{~A}_{\mathrm{E}} \mathrm{B}_{\mathrm{L}}\right)+P\left(\mathrm{~A}_{\mathrm{L}} \mathrm{B}_{\mathrm{T}}\right)
$$

which leads to:

$$
R=\frac{4 t}{2 t+l}(1-a)
$$

Eqs. (7), (21), (24) lead to the following relation between the run-fraction and the degree of randomness:

$R=2 B P\left(\mathrm{~B}_{\mathrm{L}}\right) P\left(\mathrm{~B}_{\mathrm{T}}\right)$

showing that $R$ is a simple linear function of $B$. 
Theil's randomness parameter, $Q$

Theil's $Q$ parameter, introduced for equilibrium chain copolymerizations [21], is defined as the reciprocal of the equilibrium constant of the reaction that creates $X-Y$ and $Y-X$ hetero-type linkages between $X$ and $Y$ units from $X-X$ and $Y-Y$ homo-type linkages. It is written:

$Q=\frac{P_{\mathrm{XX}} P_{Y Y}}{P_{\mathrm{XY}} P_{\mathrm{YX}}}$

where $P_{\mathrm{XY}}$ is the probability of finding a $\mathrm{Y}$ unit next to an $\mathrm{X}$ unit. In the case of PET$P C L$ copolyesters, the reaction that creates $B_{T}-A_{L}$ and $B_{L}-A_{E}$ hetero-type ester bonds from $B_{T}-A_{E}$ and $B_{L}-A_{L}$ homo-type ones is given in Scheme 3:

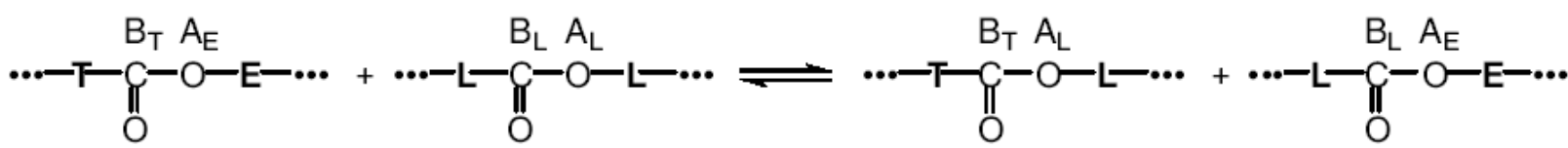

Scheme 3

Hence, $Q$ can be written:

$Q=\frac{P\left(\mathrm{~A}_{\mathrm{E}}, \mathrm{B}_{\mathrm{T}}\right) P\left(\mathrm{~A}_{\mathrm{L}} \mathrm{B}_{\mathrm{L}}\right)}{P\left(\mathrm{~A}_{\mathrm{E}} \mathrm{B}_{\mathrm{L}}\right) P\left(\mathrm{~A}_{\mathrm{L}} \mathrm{B}_{\mathrm{T}}\right)}=\frac{P\left(\mathrm{~B}_{\mathrm{T}} \mid \mathrm{A}_{\mathrm{E}}\right) P\left(\mathrm{~B}_{\mathrm{L}} \mid \mathrm{A}_{\mathrm{L}}\right)}{P\left(\mathrm{~B}_{\mathrm{L}} \mid \mathrm{A}_{\mathrm{E}}\right) P\left(\mathrm{~B}_{\mathrm{T}} \mid \mathrm{A}_{\mathrm{L}}\right)}$

and:

$Q=\frac{a(l-2 t(1-a))}{2 t(1-a)^{2}}$

The value of $Q$ is 1 for random copolymers, 0 for fully alternating copolymers $(a=0)$ and increases without limit for mixtures of homopolymers or for block-copolymers with very long sequences $(a=1)$.

Since $Q$ is an equilibrium constant, it is only a function of the free enthalpy change associated to the creation of hetero-type bonds from homo-type ones and, unlike $B$, does not depend upon copolymer composition, provided that equilibrium is reached. It has been suggested [21] that the concurrent listing of both $B$ and $Q$ would more adequately describe the sequence length distribution of a copolymer than either used alone.

\section{Number-average block lengths}

PET-PCL can be regarded as copolymers containing hard (PET) and soft (PCL) blocks. The number-average length of PET blocks, $\overline{L_{n, E T}}$, is defined as the number-average number of terephthalate $(T)$ and 1,2-ethylene $(E)$ monomer units in ET-type sequences. A similar definition applies for the number-average length of PCL blocks, $\overline{L_{n, \mathrm{~L}}}$, defined as the number-average number of $\mathrm{L}$ monomer units in $\mathrm{L}$-type sequences.

$T$ and $E$ units may be present as isolated units linked to two L-type sequences. Such isolated units will be considered as ET-type 'blocks' of length $=1$, decreasing the PCL average block length. For instance, the sequence "..LLLTLLLLL." will be 
regarded as a succession of one L-type block of length $=3$, one ET-type 'block' of length $=1$ and one L-type block of length $=5$. Similar definitions will apply for isolated $E$ and $L$ units.

According to these definitions, the number-average length of PET blocks is equal to the total number of $E+T$ units divided by the number of ET-type blocks. The number of ET-type blocks is obviously half the number of blocks, which in turn is equal to the number of hetero-type ester bonds. Therefore:

$\overline{L_{n, \mathrm{ET}}}=\frac{N(\mathrm{E})+N(\mathrm{~T})}{\left(N\left(\mathrm{~A}_{\mathrm{E}} \mathrm{B}_{\mathrm{L}}\right)+N\left(\mathrm{~A}_{\mathrm{L}} \mathrm{B}_{\mathrm{T}}\right)\right) / 2}$

Introducing the conditional probabilities:

$\overline{L_{n, \mathrm{ET}}}=\frac{2}{P\left(\mathrm{~B}_{\mathrm{L}} \mid \mathrm{A}_{\mathrm{E}}\right)+P\left(\mathrm{~A}_{\mathrm{L}} \mid \mathrm{B}_{\mathrm{T}}\right)}=\frac{1}{P\left(\mathrm{~A}_{\mathrm{L}} \mid \mathrm{B}_{\mathrm{T}}\right)}=\frac{1}{1-P\left(\mathrm{~A}_{\mathrm{E}} \mid \mathrm{B}_{\mathrm{T}}\right)}=\frac{1}{1-a}$

Similarly:

$\overline{L_{n, \mathrm{~L}}}=\frac{1}{P\left(\mathrm{~A}_{\mathrm{E}} \mid \mathrm{B}_{\mathrm{L}}\right)}=\frac{1}{1-P\left(\mathrm{~A}_{\mathrm{L}} \mid \mathrm{B}_{\mathrm{L}}\right)}=\frac{l}{2 t(1-a)}$

In the case of a random distribution, $a=P\left(\mathrm{~B}_{\mathrm{T}}\right)=P\left(\mathrm{~A}_{\mathrm{E}}\right)=2 t /(2 t+l)$, which leads to:

$\left(\overline{L_{n, \mathrm{ET}}}\right)_{\text {random }}=\frac{1}{P\left(\mathrm{~A}_{\mathrm{L}}\right)}=\frac{2 t+l}{l}$

and $\left(\overline{L_{n, \mathrm{~L}}}\right)_{\text {random }}=\frac{1}{P\left(\mathrm{~A}_{\mathrm{E}}\right)}=\frac{2 t+l}{2 t}$

Eqs. (21), (31), (32) lead to a relationship between the average sequence lengths and the degree of randomness that is also known to apply to condensation copolymers from symmetrical monomers [1,2]:

$B=\frac{1}{\overline{L_{n, \mathrm{ET}}}}+\frac{1}{\overline{L_{n, \mathrm{~L}}}}$

\section{Ratio of random/observed block lengths}

The ratio of random/observed block lengths has been used as a parameter to quantify randomness in poly(glycolide)-PCL copolymers [28]. Eqs. (21) and (29) show that this parameter is another expression of the degree of randomness $B$ :

$r=\frac{\left(L_{n, \mathrm{ET}}\right)_{\text {random }}}{L_{n, \mathrm{ET}}}=\frac{P\left(\mathrm{~A}_{\mathrm{L}} \mid \mathrm{B}_{\mathrm{T}}\right)}{P\left(\mathrm{~A}_{\mathrm{L}}\right)}=B$

\section{Randomness number, $\Psi\left(X_{\mathrm{OB}}\right)$}

This parameter was introduced for copolyesters of PET and poly(4-hydroxybenzoic acid) (PHB) [36], i.e., three-component copolyesters with one unsymmetrical unit, exhibiting the same type of theoretical microstructure as PET-PCL copolymers. $\Psi\left(X_{\mathrm{OB}}\right)$ was calculated from ${ }^{1} \mathrm{H}$ and ${ }^{13} \mathrm{C}$ NMR measurements of dyad numberfractions and defined as: 


$$
\Psi\left(X_{\mathrm{OB}}\right)=\frac{\alpha\left(X_{\mathrm{OB}}\right)-\alpha^{\circ}\left(X_{\mathrm{OB}}\right)}{1-\alpha^{\circ}\left(X_{\mathrm{OB}}\right)}
$$

where $\alpha\left(X_{\mathrm{OB}}\right)$ is the number-fraction of $-\mathrm{O}$ - groups of PHB units connected to - $\mathrm{CO}-$ groups of other PHB units and $\alpha^{\circ}\left(X_{\mathrm{OB}}\right)$ the value of this number-fraction in a totally random copolymer. Noting $A_{L}$ and $B_{L}$, respectively, the -O- and -CO- groups of PHB units (unsymmetrical units) and using definitions (6) and (7), Eq. (37) leads to:

$$
\Psi\left(X_{\mathrm{OB}}\right)=\frac{P\left(\mathrm{~B}_{\mathrm{L}} \mid \mathrm{A}_{\mathrm{L}}\right)-\left(P\left(\mathrm{~B}_{\mathrm{L}} \mid \mathrm{A}_{\mathrm{L}}\right)\right)_{\text {random }}}{1-\left(P\left(\mathrm{~B}_{\mathrm{L}} \mid \mathrm{A}_{\mathrm{L}}\right)\right)_{\text {random }}}=\frac{P\left(\mathrm{~B}_{\mathrm{L}} \mid \mathrm{A}_{\mathrm{L}}\right)-P\left(\mathrm{~B}_{\mathrm{L}}\right)}{P\left(\mathrm{~B}_{\mathrm{T}}\right)}
$$

Since $P\left(\mathrm{~B}_{\mathrm{L}} \mid \mathrm{A}_{\mathrm{L}}\right)=1-P\left(\mathrm{~B}_{\mathrm{T}} \mid \mathrm{A}_{\mathrm{L}}\right)$ (Eq. (13)), it is easy to show that the randomness number $\Psi\left(X_{\mathrm{OB}}\right)$ is a simple linear function of the degree of randomness $B$ :

$\Psi\left(X_{\mathrm{OB}}\right)=1-B$

$\Psi\left(X_{\mathrm{OB}}\right)=0$ for random copolymers, $\Psi\left(X_{\mathrm{OB}}\right)=1$ for mixtures of homopolymers or block-copolymers with very long blocks, and $\Psi\left(X_{\mathrm{OB}}\right)=-0.5$ and -1 for $\cdots$ TELTELTEL $\cdots$ and $\cdots$ LTLELTLE $\cdots$ alternating copolymers, respectively.

\section{Preference factor, $m$}

The preference factor, $m$, was used to characterize the sequence distributions in poly(butylene terephthalate)-PHB copolymers (PBT-PHB) [33], i.e., a case quite similar to the previous one. With the notations used above for PET-PHB copolymers, $m$ was defined as the ratio $\alpha\left(X_{\mathrm{OB}}\right) / \alpha^{\circ}\left(X_{\mathrm{OB}}\right)$. With the conditional probabilities:

$m=\frac{P\left(\mathrm{~B}_{\mathrm{L}} \mid \mathrm{A}_{\mathrm{L}}\right)}{\left(P\left(\mathrm{~B}_{\mathrm{L}} \mid \mathrm{A}_{\mathrm{L}}\right)\right)_{\text {random }}}=\frac{P\left(\mathrm{~B}_{\mathrm{L}} \mid \mathrm{A}_{\mathrm{L}}\right)}{P\left(\mathrm{~B}_{\mathrm{L}}\right)}$

the relationship between $B$ and $m$ is easily drawn from Eqs. (9), (13) and (21):

$m=1+\frac{2 t}{l}(1-B)$

It must be pointed out that $B$ could be directly obtained in these PHB copolymers by dividing $1-\alpha\left(X_{\mathrm{OB}}\right)$ by its theoretical value for a random copolymer, $1-\alpha^{\circ}\left(X_{\mathrm{OB}}\right)$.

\section{Sequence order parameter, $\Psi$}

The sequence order parameter $\Psi$ was defined for copolyesters of PHB and poly(6hydroxy-2-naphthoic acid) (PHN) [29] as:

$\Psi=\frac{(\mathrm{BN}) \mathrm{X}-(\mathrm{BB})(1-\mathrm{X})}{(\mathrm{BN}) \mathrm{X}+(\mathrm{BB})(1-\mathrm{X})}$

where (BN) and (BB) are, respectively, the number-fractions of PHB-PHN and PHBPHB dyads in copolymer and $X$ is the number-fraction of PHB units. The experimental values of dyad number-fractions were determined by integration of the corresponding carbonyl ${ }^{13} \mathrm{C}$ NMR resonances. Since the dyad number-fractions can be expressed as functions of conditional probabilities (see below), the definition of $\Psi$ is readily extended to PET-PCL copolymers by the following equation: 
$\Psi=\frac{P\left(\mathrm{~A}_{\mathrm{L}}, \mathrm{B}_{\mathrm{T}}\right) P\left(\mathrm{~B}_{\mathrm{T}}\right)-P\left(\mathrm{~A}_{\mathrm{E}}, \mathrm{B}_{\mathrm{T}}\right) P\left(\mathrm{~B}_{\mathrm{L}}\right)}{P\left(\mathrm{~A}_{\mathrm{L}}, \mathrm{B}_{\mathrm{T}}\right) P\left(\mathrm{~B}_{\mathrm{T}}\right)+P\left(\mathrm{~A}_{\mathrm{E}}, \mathrm{B}_{\mathrm{T}}\right) P\left(\mathrm{~B}_{\mathrm{L}}\right)}=\frac{P\left(\mathrm{~B}_{\mathrm{T}} \mid \mathrm{A}_{\mathrm{L}}\right)-P\left(\mathrm{~B}_{\mathrm{T}} \mid \mathrm{A}_{\mathrm{E}}\right)}{P\left(\mathrm{~B}_{\mathrm{T}} \mid \mathrm{A}_{\mathrm{L}}\right)+P\left(\mathrm{~B}_{\mathrm{T}} \mid \mathrm{A}_{\mathrm{E}}\right)}$

which can also be written from Eqs. (16) - (19):

$\Psi=\frac{2 t-a(2 t+l)}{2 t-a(2 t-l)}$

The relationship between the sequence order parameter and the degree of randomness in PET-PCL copolyesters is given by:

$\Psi=\frac{B-1}{1+B \frac{2 t-l}{2 t+l}}$

$\Psi=0$ for random copolyesters, $\Psi=-1$ for mixtures of homopolyesters or blockcopolymers with very long blocks, and $\Psi=1 / 3$ or 1 for $\cdots$ TELTELTEL $\cdots$ or $\cdots$ LTLELTLE $\cdots$ alternating copolymers, respectively.

Eq. (43) is also of general application and can be used for the three- and fourcomponent condensation copolymers discussed above, as well as for copolyesters obtained from mixtures of AB-type monomers.

\section{Weight-average block lengths}

To our knowledge, the weight-average block lengths $\overline{L_{w}}$ have never been examined for copolymers containing both symmetrical and unsymmetrical monomer units. They can readily be obtained using the recursive statistical approach that Macosko et al. developed [37] and applied to condensation copolymers containing two unsymmetrical AB-type monomer units or three symmetrical ones [38].

According to the notations of ref. [38], the weight-average length of L-type blocks in PET-PCL copolymers is given by:

$\overline{L_{w, \mathrm{~L}}}=1+E\left(N_{\mathrm{L}, \mathrm{B} \mathrm{L}}^{\text {out }}\right)+E\left(N_{\mathrm{L}, \mathrm{A}_{\mathrm{L}}}^{\text {out }}\right)$

where $E\left(N_{\mathrm{L}, \mathrm{B}_{\mathrm{L}}}^{\text {out }}\right)$ is the expected number (average number) of $\mathrm{L}$ units sequentially attached to a $B_{L}$ group looking out from its parent molecule (Scheme 4).

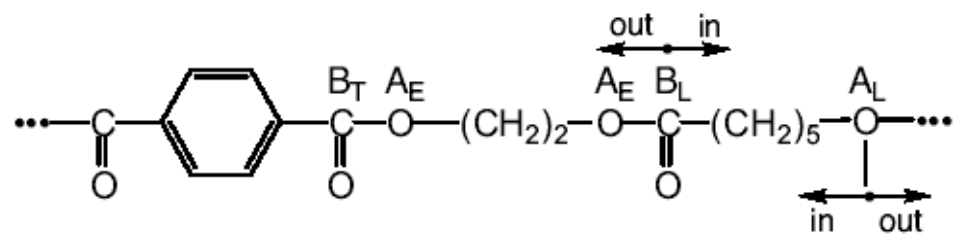

Scheme 4

A similar definition applies for $E\left(N_{\mathrm{L}, A_{\mathrm{L}}}^{\text {out }}\right)$. According to the total probability law, $E\left(N_{\mathrm{L}, \mathrm{B}_{\mathrm{L}}}^{\text {out }}\right)$ is given by Eq. $(47)$, where $E\left(N_{\mathrm{L}, \mathrm{A}_{\mathrm{i}}}^{\mathrm{in}}\right)$ is the expected number of $\mathrm{L}$ units sequentially attached to an $A_{i}$ group looking into its parent molecule $(i=L, E)$. Since an $L$ block terminates when an $A_{E}$ group is attached to a $B_{L}$ group, $E\left(N_{L, A_{E}}^{\text {in }}\right)=0$. 
$E\left(N_{\mathrm{L}, \mathrm{B}_{\mathrm{L}}}^{\text {out }}\right)=E\left(N_{\mathrm{L}, \mathrm{A}_{\mathrm{L}}}^{\text {in }}\right) P\left(\mathrm{~A}_{\mathrm{L}} \mid \mathrm{B}_{\mathrm{L}}\right)+\overbrace{E\left(N_{\mathrm{L}, \mathrm{A}_{\mathrm{E}}}^{\text {in }}\right)}^{=0} P\left(\mathrm{~A}_{\mathrm{E}} \mid \mathrm{B}_{\mathrm{L}}\right)$

Similarly:

$$
E\left(N_{\mathrm{L}, \mathrm{A}_{\mathrm{L}}}^{\text {out }}\right)=E\left(N_{\mathrm{L}, \mathrm{B}_{\mathrm{L}}}^{\text {in }}\right) P\left(\mathrm{~B}_{\mathrm{L}} \mid \mathrm{A}_{\mathrm{L}}\right)
$$

and:

$$
\begin{aligned}
& E\left(N_{\mathrm{L}, \mathrm{A}_{\mathrm{L}}}^{\text {in }}\right)=1+E\left(N_{\mathrm{L}, \mathrm{B}_{\mathrm{L}}}^{\text {out }}\right) \\
& E\left(N_{\mathrm{L}, \mathrm{B}_{\mathrm{L}}}^{\text {in }}\right)=1+E\left(N_{\mathrm{L}, \mathrm{B}_{\mathrm{L}}}^{\text {out }}\right)
\end{aligned}
$$

$\overline{L_{w, \mathrm{~L}}}$ is calculated from Eq. (46) and the set of 4 equations in 4 unknowns (47) - (50):

$\overline{L_{w, \mathrm{~L}}}=\frac{1+P\left(\mathrm{~A}_{\mathrm{L}} \mid \mathrm{B}_{\mathrm{L}}\right)}{1-P\left(\mathrm{~A}_{\mathrm{L}} \mid \mathrm{B}_{\mathrm{L}}\right)}$

The same method gives $\overline{L_{w, \mathrm{ET}}}$ :

$\overline{L_{w, \mathrm{ET}}}=\frac{1+P\left(\mathrm{~A}_{\mathrm{E}} \mid \mathrm{B}_{\mathrm{T}}\right)}{1-P\left(\mathrm{~A}_{\mathrm{E}} \mid \mathrm{B}_{\mathrm{T}}\right)}$

The same expressions were derived for condensation copolymers with three symmetrical monomer units or with two unsymmetrical monomer units [38].

\section{Conclusion}

The use of probabilities relative to functional groups provides a much more easy way of evaluating the 'randomness' or the 'blockiness' of condensation copolymers than probabilities involving monomer units. This method avoids the cumbersome mathematical considerations required when unsymmetrical monomer units are present in copolymer chains, and gives a very simple expression of Yamadera and Murano's degree of randomness $B$. The number- and weight-average block lengths and a variety of randomness parameters introduced in the literature for the study of such copolymers were also readily calculated and compared.

Most parameters turn out to be either different formulations, or simple linear or rational functions of the degree of randomness $B$. This parameter is directly connected to a definition of elementary probability theory (event independence) and appears to be the most useful parameter for characterizing randomness in condensation copolymers. The slightly different 'randomness number' (Eq. (39)) and the more complex 'preference factor' (Eq. (41)) and 'sequence order parameter' (Eq. (45)) give essentially similar information on copolymer microstructure.

It is worth remarking that $B$ and its related parameters are composition-dependent. This means that they cannot be used to compare the departure from randomness of copolyesters having different compositions (unless $B=1$ ). On the other hand, Theil's $Q$ parameter was introduced as composition-independent and could bring interesting information when studying randomization as a function of comonomer mole ratio. However, it must be stressed that $Q$ was defined for equilibrium copolymerizations and that meaningful comparisons of departure from randomness using this parameter could be done only when equilibrium is reached. Although this does not necessarily imply that a random distribution is obtained, it is a rather severe limitation. 
Run-number $R$ and average block-lengths are composition-dependent and do not directly characterize randomness, unless they are compared to their theoretical values for random copolymers. However, since they correlate well with the ability of a copolymer to crystallize, they could be of interest in discussions of copolymer mechanical or thermomechanical properties.

This approach of randomness based on functional group probabilities has been introduced and described taking PET-PCL copolyesters as an example. It obviously applies for any $A A+B B+A B$ condensation copolymers such as polyamides or copolyester-amides. Moreover, the relations giving $B, Q$ and the average block lengths are quite general and also applicable to three- and four-component condensation copolymers.

\section{Appendix}

\section{Determination of dyad and triad number-fractions in PET-PCL copolymers}

The analysis of NMR spectra provides information on the number-fractions of triads and dyads present in copolymer chains. In order to experimentally determine the randomness parameters and the average block lengths, relationships between dyad and triad number-fractions and the $P\left(\mathrm{~A}_{\mathrm{i}} \mid \mathrm{B}_{\mathrm{j}}\right)$ probabilities should be established.

\section{Dyad number-fractions}

The total number of dyads found when examining the polymer chain from one end to the other is equal to the total number of monomer units, i.e., to the total number of $A$ groups (or $B$ groups). The number of ET and TE dyads in polymer chains is equal to the number of $A_{E}-B_{T}+B_{T}-A_{E}$ linkages. Therefore, the number-fraction $F(E T+T E)$ of ET and TE dyads is given by:

$$
F(\mathrm{ET}+\mathrm{TE})=\frac{N(\mathrm{ET}+\mathrm{TE})}{N(\mathrm{~A})}=\frac{N\left(\mathrm{~A}_{\mathrm{E}}, \mathrm{B}_{\mathrm{T}}\right)}{N(\mathrm{~A})}=P\left(\mathrm{~A}_{\mathrm{E}}, \mathrm{B}_{\mathrm{T}}\right)
$$

Similar relationships hold for $F(\mathrm{EL}+\mathrm{LE})$ and $F(\mathrm{LT}+\mathrm{TL})$. Remarking that the number of $L L$ dyads is equal to the number of $A_{L}-B_{L}+B_{L}-A_{L}$ linkages, it follows from Eqs. (5-7):

$$
\begin{aligned}
& F(\mathrm{ET}+\mathrm{TE})=P\left(\mathrm{~A}_{\mathrm{E}}\right) P\left(\mathrm{~B}_{\mathrm{T}} \mid \mathrm{A}_{\mathrm{E}}\right)=P\left(\mathrm{~B}_{\mathrm{T}}\right) P\left(\mathrm{~A}_{\mathrm{E}} \mid \mathrm{B}_{\mathrm{T}}\right) \\
& F(\mathrm{EL}+\mathrm{LE})=P\left(\mathrm{~A}_{\mathrm{E}}\right) P\left(\mathrm{~B}_{\mathrm{L}} \mid \mathrm{A}_{\mathrm{E}}\right)=P\left(\mathrm{~B}_{\mathrm{L}}\right) P\left(\mathrm{~A}_{\mathrm{E}} \mid \mathrm{B}_{\mathrm{L}}\right) \\
& F(\mathrm{LT}+\mathrm{TL})=P\left(\mathrm{~A}_{\mathrm{L}}\right) P\left(\mathrm{~B}_{\mathrm{T}} \mid \mathrm{A}_{\mathrm{L}}\right)=P\left(\mathrm{~B}_{\mathrm{T}}\right) P\left(\mathrm{~A}_{\mathrm{L}} \mid \mathrm{B}_{\mathrm{T}}\right) \\
& F(\mathrm{LL})=P\left(\mathrm{~A}_{\mathrm{L}}\right) P\left(\mathrm{~B}_{\mathrm{L}} \mid \mathrm{A}_{\mathrm{L}}\right)=P\left(\mathrm{~B}_{\mathrm{L}}\right) P\left(\mathrm{~A}_{\mathrm{L}} \mid \mathrm{B}_{\mathrm{L}}\right)
\end{aligned}
$$

${ }^{13} \mathrm{C}$ NMR gives usually straightforward information on the $F$ number-fractions. For example, the $\mathrm{CO}$ resonances are frequently used to discuss polyester or polyamide chain microstructure. The $F$ number-fractions are obviously equal to the normalized integrations of each $\mathrm{CO}$ peak with respect to the total $\mathrm{CO}$ peak integration. From Eqs. (16) - (19) and (54) - (57), it is thus possible to obtain the values of the $P\left(\mathrm{~A}_{\mathrm{i}} \mid \mathrm{B}_{\mathrm{j}}\right)$ probabilities.

In some other cases, the most accessible values are those of the dyad numberfractions $F_{i}$ relative to a given monomer unit i. The number-fraction $F_{E}(\mathrm{ET}+\mathrm{TE})$ of $E T+T E$ dyads in E-containing dyads is equal to the number of $A_{E}-B_{T}+B_{T}-A_{E}$ 
linkages divided by the number of $A_{E}$-containing linkages, i.e., to the conditional probability $P\left(\mathrm{~B}_{\mathrm{T}} \mid \mathrm{A}_{\mathrm{E}}\right)$ :

$$
F_{E}(\mathrm{ET}+\mathrm{TE})=\frac{N\left(\mathrm{~A}_{\mathrm{E}} \mathrm{B}_{\mathrm{T}}\right)}{\sum_{\mathrm{j}=\mathrm{T}, \mathrm{L}} N\left(\mathrm{~A}_{\mathrm{E}} \mathrm{B}_{\mathrm{j}}\right)}=\frac{N\left(\mathrm{~A}_{\mathrm{E}}, \mathrm{B}_{\mathrm{T}}\right)}{N\left(\mathrm{~A}_{\mathrm{E}}\right)}=P\left(\mathrm{~B}_{\mathrm{T}} \mid \mathrm{A}_{\mathrm{E}}\right)
$$

Similar definitions and relationships apply for $F_{E}(E L+L E)$ and for the $F_{T}$ dyad fractions $F_{T}(\mathrm{TE}+\mathrm{ET})$ and $F_{T}(\mathrm{TL}+\mathrm{LT})$ :

$$
\begin{array}{ll}
F_{E}(\mathrm{Ei}+\mathrm{iE})=P\left(\mathrm{~B}_{\mathrm{i}} \mid \mathrm{A}_{\mathrm{E}}\right) & (\mathrm{i}=\mathrm{T}, \mathrm{L}) \\
F_{T}(\mathrm{Ti}+\mathrm{iT})=P\left(\mathrm{~A}_{\mathrm{i}} \mid \mathrm{B}_{\mathrm{T}}\right) & (\mathrm{i}=\mathrm{E}, \mathrm{L})
\end{array}
$$

Since an $L$ unit may be linked to other $L$ units, the number of $L$-containing dyads is lower than the number of $L$ functional groups. Therefore, $F_{L}(L E+E L)$ is not equal to the conditional probability $P\left(\mathrm{~A}_{\mathrm{E}} \mid \mathrm{B}_{\mathrm{L}}\right)$ :

$$
F_{L}(\mathrm{LE}+\mathrm{EL})=\frac{N\left(\mathrm{~A}_{\mathrm{E}}, \mathrm{B}_{\mathrm{L}}\right)}{N\left(\mathrm{~A}_{\mathrm{L}}, \mathrm{B}_{\mathrm{T}}\right)+N\left(\mathrm{~A}_{\mathrm{E}}, \mathrm{B}_{\mathrm{L}}\right)+N\left(\mathrm{~A}_{\mathrm{L}}, \mathrm{B}_{\mathrm{L}}\right)}
$$

which leads to:

$$
F_{L}(\mathrm{LE}+\mathrm{EL})=\frac{P\left(\mathrm{~A}_{\mathrm{E}} \mid \mathrm{B}_{\mathrm{L}}\right)}{1+P\left(\mathrm{~A}_{\mathrm{E}} \mid \mathrm{B}_{\mathrm{L}}\right)}
$$

Similarly:

$$
\begin{aligned}
& F_{L}(\mathrm{LT}+\mathrm{TL})=\frac{P\left(\mathrm{~B}_{\mathrm{T}} \mid \mathrm{A}_{\mathrm{L}}\right)}{1+P\left(\mathrm{~B}_{\mathrm{T}} \mid \mathrm{A}_{\mathrm{L}}\right)}=F_{L}(\mathrm{LE}+\mathrm{EL}) \\
& F_{L}(\mathrm{LL})=\frac{P\left(\mathrm{~A}_{\mathrm{L}} \mid \mathrm{B}_{\mathrm{L}}\right)}{1+P\left(\mathrm{~A}_{\mathrm{E}} \mid \mathrm{B}_{\mathrm{L}}\right)}
\end{aligned}
$$

\begin{tabular}{|c|c|c|c|}
\hline j & $E$ & $L$ & $\bar{T}$ \\
\hline$E$ & - & $\frac{2 t(1-a)}{l+2 t(1-a)}$ & $a$ \\
\hline $\mathrm{L}$ & $(1-a)$ & $\frac{l-2 t(1-a)}{l+2 t(1-a)}$ & $(1-a)$ \\
\hline $\mathrm{T}$ & $a$ & $\frac{2 t(1-a)}{l+2 t(1-a)}$ & - \\
\hline
\end{tabular}

Again, if one of the $F_{i}$ number-fractions is experimentally known, all the conditional probabilities can be calculated (Tab. 1).

Tab. 1. Values of dyad number-fractions $F_{i}(\mathrm{ij}+\mathrm{ji})$ in PET-PCL copolymers as functions of $P\left(\mathrm{~B}_{\mathrm{T}} \mid \mathrm{A}_{\mathrm{E}}\right)=a$ and of the mole ratio $t / l$ of $\mathrm{T}$ and $\mathrm{L}$ units 
Triad number-fractions

The number-fractions of k-centred ikj or jki triads, $F(\mathrm{ikj}+\mathrm{jki})$ and $F_{k}(\mathrm{ikj}+\mathrm{jki})$, are defined by Eqs. (65) and (66), where $N(\mathrm{ikj}+\mathrm{jki})$ is the number of ikj + jki triads (or the number of iki triads when $\mathrm{i}=\mathrm{j})$ and $N(\mathrm{k})$ the number of $\mathrm{k}$ units $(\mathrm{k}=\mathrm{E}, \mathrm{T}, \mathrm{L})$.

$F_{k}(\mathrm{ikj}+\mathrm{jki})=\frac{N(\mathrm{ikj}+\mathrm{jki})}{\sum_{\mathrm{i}, \mathrm{j}} N(\mathrm{ikj}+\mathrm{jki})}=\frac{N(\mathrm{ikj}+\mathrm{jki})}{N(\mathrm{k})}$

$F(\mathrm{ikj}+\mathrm{jki})=\frac{N(\mathrm{ikj}+\mathrm{jki})}{\sum_{\mathrm{k}} N(\mathrm{k})}$

$(k=E, T ; i, j \neq k) ;(k=L ; i \neq j$ or $i=j=L)$

Tab. 2. Theoretical triad number-fractions $F_{k}(\mathrm{ikj}+\mathrm{jki})$ of k-centred triads in PET-PCL copolyesters, assuming that substitutions on both sides of unit $k$ are independent. Values as functions of $P\left(\mathrm{~B}_{\mathrm{T}} \mid \mathrm{A}_{\mathrm{E}}\right)=a$ and of the mole ratio $t / l$ of $\mathrm{T}$ and $\mathrm{L}$ units

\begin{tabular}{lll}
\hline Triad number-fractions & $F_{E}(\mathrm{ikj})$ expressions & $F_{E}(\mathrm{ikj})$ values \\
\hline$F_{E}(\mathrm{TET})$ & $P\left(\mathrm{~B}_{\mathrm{T}} \mid \mathrm{A}_{\mathrm{E}}\right)^{2}$ & $a^{2}$ \\
$F_{E}(\mathrm{TEL}+\mathrm{LET})$ & $2 P\left(\mathrm{~B}_{\mathrm{T}} \mid \mathrm{A}_{\mathrm{E}}\right) P\left(\mathrm{~B}_{\mathrm{L}} \mid \mathrm{A}_{\mathrm{E}}\right)$ & $2 a(1-a)$ \\
$F_{E}(\mathrm{LEL})$ & $P\left(\mathrm{~B}_{\mathrm{L}} \mid \mathrm{A}_{\mathrm{E}}\right)^{2}$ & $(1-a)^{2}$ \\
\hline$F_{T}(\mathrm{ETE})=F_{E}(\mathrm{TET})$ & $P\left(\mathrm{~A}_{\mathrm{E}} \mid \mathrm{B}_{\mathrm{T}}\right)^{2}$ & $d^{2}$ \\
$F_{T}(\mathrm{ETL}+\mathrm{LTE})=F_{E}(\mathrm{TEL}+\mathrm{LET})$ & $2 P\left(\mathrm{~A}_{\mathrm{E}} \mid \mathrm{B}_{\mathrm{T}}\right) P\left(\mathrm{~A}_{\mathrm{L}} \mid \mathrm{B}_{\mathrm{T}}\right)$ & $2 a(1-a)$ \\
$F_{T}(\mathrm{LTL})=F_{E}(\mathrm{LEL})$ & $P\left(\mathrm{~A}_{\mathrm{L}} \mid \mathrm{B}_{\mathrm{T}}\right)^{2}=$ & $d^{2}$ \\
\hline$F_{L}(\mathrm{LLL})$ & $P\left(\mathrm{~A}_{\mathrm{L}} \mid \mathrm{B}_{\mathrm{L}}\right)^{2}$ & $\left(1-\frac{2 t}{l}(1-a)\right)^{2}$ \\
$F_{L}(\mathrm{LLE}+\mathrm{ELL})$ & $P\left(\mathrm{~B}_{\mathrm{L}} \mid \mathrm{A}_{\mathrm{L}}\right) P\left(\mathrm{~A}_{\mathrm{E}} \mid \mathrm{B}_{\mathrm{L}}\right)$ & $\left(1-\frac{2 t}{l}(1-a)\right)\left(\frac{2 t}{l}(1-a)\right)$ \\
$F_{L}(\mathrm{TLE}+\mathrm{ELT})$ & $P\left(\mathrm{~B}_{\mathrm{T}} \mid \mathrm{A}_{\mathrm{L}}\right) P\left(\mathrm{~A}_{\mathrm{E}} \mid \mathrm{B}_{\mathrm{L}}\right)$ & $\left(\frac{2 t}{l}(1-a)\right)^{2}$ \\
$F_{L}(\mathrm{LLT}+\mathrm{TLL})=F_{L}(\mathrm{LLE}+\mathrm{ELL})$ & $P\left(\mathrm{~B}_{\mathrm{T}} \mid \mathrm{A}_{\mathrm{L}}\right) P\left(\mathrm{~A}_{\mathrm{L}} \mid \mathrm{B}_{\mathrm{L}}\right)$ & $\left(\frac{2 t}{l}(1-a)\right)\left(1-\frac{2 t}{l}(1-a)\right)$
\end{tabular}

In PET-PCL copolymers, the ${ }^{1} \mathrm{H}$ NMR resonances of the $E$ units depend on their two neighbouring units. The number-fractions of E-centred triads $F_{E}(\mathrm{TET})$ and $F_{E}(\mathrm{TEL}+\mathrm{LET})$ can be very easily obtained from the normalized integrations of the corresponding ${ }^{1} \mathrm{H}$ NMR resonances. A TET triad contains one TE and one ET dyad, and a TEL+LET triad contains one TE or one ET dyad. Since the number of 
E-containing dyads is twice the number of E-centred triads, the number fraction of ET+TE dyads is given by:

$$
F_{E}(\mathrm{ET}+\mathrm{TE})=F_{E}(\mathrm{TET})+\frac{F_{E}(\mathrm{TEL}+\mathrm{LET})}{2}=P\left(\mathrm{~B}_{\mathrm{T}} \mid \mathrm{A}_{\mathrm{E}}\right)=a
$$

Therefore, if the triad distribution of $\mathrm{E}$ (or $\mathrm{T}$ ) is known, all conditional probabilities can be calculated from Eqs. (16) - (19) and (67).

Even if only one of the triad number-fractions is known, e.g., $F_{E}(\mathrm{TET})$, the $P\left(\mathrm{~B}_{\mathrm{i}} \mid \mathrm{A}_{\mathrm{k}}\right)$ probabilities can be calculated, assuming that, in all the triads, the substitution on one side of a central unit does not influence the substitution on the other side. This supposes that all reactive groups of the same type $\left(A_{E}, A_{L}, B_{T}\right.$ or $\left.B_{L}\right)$ react equally, but does not assume the equal reactivity of $A_{E}$ and $A_{L}$ with a given $B$ group and the equal reactivity of $B_{T}$ and $B_{L}$ with a given $A$ group. This assumption is equivalent to the well-known hypothesis of functional group equireactivity, which is verified for most condensation polymers, especially for polymers such as polyesters and polyamides.

From Eqs. (16) - (19), the values of the $F_{k}(\mathrm{ikj})$ can be expressed as functions of the value of $P\left(\mathrm{~B}_{\mathrm{T}} \mid \mathrm{A}_{\mathrm{E}}\right)=a($ Tab. 2).

[1] Yamadera, R.; Murano, M.; J. Polym. Sci., Part A1 1967, 5, 2259.

[2] Devaux, J.; Godard, P.; Mercier, J. P.; J. Polym. Sci., Polym. Phys. Ed. 1982, 20, 1875.

[3] Kint, D. P. R.; Alla, A.; Deloret, E.; Campos, J. L.; Munoz-Guerra, S.; Polymer 2003, 44, 1321.

[4] Po, R.; Cioni, P.; Abis, L.; Occhiello, E.; Garbassi, F.; Polym. Commun. 1991, 32, 208.

[5] Montaudo, G.; Montaudo, M. S.; Scamporrino, E.; Vitalini, D.; Macromolecules 1992, 25, 5099.

[6] Abis, L.; Po, R.; Spera, S.; Bacchilega, G.; Occhiello, E.; Garbassi, F.; Makromol. Chem. 1992, 193, 1859.

[7] Jun, H. W.; Chae, S. H.; Park, S. S.; Myung, H. S.; Im, S. S.; Polymer 1999, 40, 1473.

[8] Martinez de Ilarduya, A.; Kint, D. P. R.; Muñoz-Guerra, S.; Macromolecules 2000, 33, 4596.

[9] Miley, D. M.; Runt, J.; Polymer 1992, 33, 4643.

[10] Matsuda, H.; Asakura, T.; Miki, T.; Macromolecules 2002, 35, 4664.

[11] Newmark, R. A.; J. Polym. Sci., Polym. Chem. Ed. 1980, 18, 559.

[12] Kang, H. J.; Park, S. S.; J. Appl. Polym. Sci. 1999, 72, 593.

[13] Kint, D. P. R.; Martinez de llarduya, A.; Muñoz-Guerra, S.; Macromolecules 2002, 35, 314.

[14] Fernandez-Berridi, M. J.; Iruin, J. J.; Maiza, I.; Polymer 1995, 36, 1357.

[15] Kim, J. H.; Lyoo, W. S.; Ha, W. S.; J. Appl. Polym. Sci. 2001, 82, 159.

[16] Aerdts, A. M.; Eersels, K. L. L.; Groeninckx, G.; Macromolecules 1996, 29, 1041. 
[17] Devaux, J.; Godard, P.; Mercier, J. P.; Touillaux, R.; Dereppe, J. M.; J. Polym. Sci., Polym. Phys. Ed. 1982, 20, 1881.

[18] Kaji, A.; Murano, M.; Polym. J. 1990, 22, 1065.

[19] Luo, N.; Wang, D. N.; Ying, S. K.; J. Polym. Sci., Part A: Polym. Chem. 1996, 34, 2157.

[20] Harwood, H. J.; Ritchey, W. M.; Polym. Lett. 1964, 2, 601.

[21] Theil, M. H.; Macromolecules 1969, 2, 137.

[22] Lenz, R. W.; Go, S.; J. Polym. Sci., Polym. Chem. Ed. 1974, $12,1$.

[23] Franco, L.; Xenopoulos, A.; Subirana, J. A.; Puiggali, J.; J. Polym. Sci., Part A: Polym. Chem. 1995, 33, 727.

[24] Goodman, I.; Maitland, D. J.; Kehayoglou, A. H.; Eur. Polym. J. 2000, 36, 1301.

[25] Kricheldorf, H. R.; Jonté, J. M.; Berl, M.; Makromol. Chem. Suppl. 1985, 12, 25.

[26] Kricheldorf, H. R.; Kreiser, I.; Makromol. Chem. 1987, 188, 1861.

[27] Kreiser-Saunders, I.; Kricheldorf, H. R.; Macromol. Chem. Phys. 1998, 199, 1081.

[28] Kasperczyk, J.; Macromol. Chem. Phys. 1999, 200, 903.

[29] Mühlebach, A.; Johnson, R. D.; Lyerla, J.; Economy, J.; Macromolecules 1988, $21,3117$.

[30] Ma, D.; Zhang, G.; Huang, Z.; Luo, X.; J. Polym. Sci., Part A: Polym. Chem. 1998, 36, 2961.

[31] Jin, J.-I.; Chang, J.-H.; Hatada, K.; Ute, K.; Hotta, M.; Polymer 1992, 33, 1374.

[32] Kricheldorf, H. R.; Mühlhaupt, R.; Angew. Makromol. Chem. 1977, 65, 169.

[33] Kricheldorf, H. R.; Hull, W. E.; J. Macromol. Sci.-Chem. 1977, A11, 2281.

[34] Ou, C.-F.; J. Appl. Polym. Sci. 2000, 77, 949.

[35] Komber, H.; Böhme, F.; Pospiech, D.; Rätzsch, M.; Makromol. Chem. 1990, 191, 2675.

[36] Lenz, R. W.; Jin, J.-I.; Feichtinger, K. A.; Polymer 1983, 24, 327.

[37] Macosko, C. W.; Miller, D. R.; Macromolecules 1976, 9, 199.

[38] Lopez-Serrano, F.; Castro, J. M.; Macosko, C. W.; Tirell, M.; Polymer 1980, 21, 263. 